\title{
The Dynamics of International Trade Patterns
}

\author{
Paulo Bastos and Manuel Cabral \\ GEP, University of Nottingham; University of Minho
}

\begin{abstract}
This paper introduces new dynamic measures for examining changes in international trade patterns. Using data for 20 OECD countries over the 19802000 period, we show that inter-industry trade changes contrary to countries' previous specialization are frequently the dominant form of trade expansion. The econometric analysis indicates that the observed changes in trade patterns were explained by initial endowments of human-capital and industry-specific changes in labour productivity and labour costs. The results also suggest that trade liberalization induced an increase in the previous specialization of larger OECD economies in industries with increasing returns to scale. JEL no. F1, O33, O50

Keywords: Dynamics of international specialization; trade liberalization; technology transfers
\end{abstract}

\section{Introduction}

It is well known that international economic integration has proceeded at a rapid pace in recent decades. Between 1970 and 2004, trade openness increased sharply across the globe, having more than doubled in many OECD countries (OECD 2005). In spite of the potential benefits associated with this process, in recent years a growing number of observers in the advanced nations started to reveal concerns about the adverse effects of increased competition from developing countries, particularly in industries that typically belonged to developed countries. These concerns are well represented by the following statement of Freeman (2005: 3):

"Diminished comparative advantage in high-tech will create adjustment problems for US workers, of which the offshoring of IT jobs to India, growth of high-tech production and exports from China, and

Remark: The authors would like to thank Peter Wright, Mauro Pisu, Richard Upward, Joana Silva, Nuno Sousa, Paula Fontoura, Peter Egger, the participants at the 2005 Spring Midwest International Economics Meeting (Vanderbilt University) and an anonymous referee for valuable comments. The usual disclaimer applies. Please address correspondence to School of Economics, University of Nottingham, Nottingham, NG7 2RD, United Kingdom; e-mail: paulo.bastos@nottingham.ac.uk 
multinational movement of R\&D facilities to developing countries, are harbingers. The country faces a long transition to a less dominant position in science and engineering associated industries, for which the U.S. will have to develop new labor market and R\&D policies that build on existing strengths and develop new ways of benefiting from scientific and technological advances in other countries."

How does the pattern of international specialization evolve over time? Which are the drivers of the observed changes? Policy-oriented studies on trade liberalization often assume that this process can either lead to an increase in the previous specialization (inter-industry trade) or to matched trade expansion. ${ }^{1}$ The first is the path predicted by the standard trade model, the second that suggested by the models of intra-industry trade. This paper starts by introducing evidence that an important part of the trade expansion does not fit either of these two alternatives. It consists of trade expansion such that net export decreases in net export sectors and net import decreases in import competing sectors (which we call specialization shifts). We report evidence that specialization shifts are very important in the OECD, being often the dominant form of inter-industry trade expansion.

In the context of the Heckscher-Ohlin model, these changes in the pattern of trade may be explained by shifts in the underlying determinants of comparative advantage, that is, by unequal accumulation of factor endowments among trade partners. In contrast to the traditional trade theory, the theoretical models of trade and growth (Krugman 1987; Lucas 1988; Grossman and Helpman 1991; Redding 1999) and the models of the new economic geography (Fujita et al. 1999) offer a dynamic approach to explain the evolution of international specialization, providing interesting predictions about the evolution of trade patterns. One important suggestion of the trade and growth literature is that industry-specific learning by doing or cross-country differences in R\&D investments may produce self-reinforcing mechanisms that contribute to strengthen a country's previous specialization. Both these types of dynamic models, however, are consistent with an increase or a decrease in the previous specialization, depending for example on the rate of innovation and technology transfer (for the models based on technology) or on the complex relationship between transport costs to the periphery and relative factor prices (in the case of the models of the new economic geography).

1 See, for example, Baldwin et al. (1997) 
The present paper contributes to the empirical literature on the dynamics of trade patterns in several ways. We start by introducing new dynamic indexes for analysing changes in the pattern of trade. An important attribute of these measures is that they reveal both the structure and the direction of the change in trade. More specifically, they allows us to decompose the trade change into three different components: Inter-industry trade change that contributes to an increase in a country's previous specialization, marginal intra-industry trade, and inter-industry trade change that contributes to a decrease in a country's previous specialization (specialization shifts). We then apply these measures to study the dynamics of trade patterns in 20 OECD countries over the 1980-2000 period. In line with the previous empirical research on specialization dynamics (Amiti 1999; Proudman and Redding 2000; Redding 2002; Tingvall 2004), we find no evidence of a generalized increase in specialization among OECD countries. Indeed, we show that specialization shifts are very important, being often the dominant form of trade expansion. We proceed in our investigation of changes in trade patterns by using the new dynamic measures as the dependent variable in econometric analysis. Using data from 26 manufacturing industries in 20 OECD countries for the period 1980-1990, we analyse the role played by regressors based on the neoclassical trade model, the new economic geography and the models of trade and growth in explaining the observed changes in the pattern of trade.

Our analysis builds on the empirical work of many predecessors. Kim (1995) examines the importance of industry characteristics associated with the Heckscher-Ohlin and the 'new economic geography' models to explain the evolution of US regional specialization. Kim finds evidence that scale economies explain industry localization over time, while resource intensity (which aims to capture the importance of the neoclassical trade model) determines the pattern of localization across industries. Amiti (1999) conducts a related analysis for a set of EU economies. She finds evidence of increased concentration in industries with increasing returns to scale and mixed results for other industries. ${ }^{2}$ Redding (2002) examines the role of

\footnotetext{
2 In a related strand of research, Davis and Weinstein (1999) analyse the relative importance of endowments and economic geography in explaining the production structure of Japanese regions. Davis and Weinstein (2003) conduct a similar study using data for a set of OECD countries. Both studies provide evidence that factor endowments and economic geography play an important role in explaining the pattern of specialization. However, by focusing on the determinants of specialization patterns in a moment of time, these papers do not provide direct evidence on the drivers of changes in specialization.
} 
country-specific changes in endowments and common forces across countries in explaining changes in output shares across 20 industries in 7 OECD countries. His results indicate that changes in countries' factor endowments are indeed an important determinant of specialization dynamics, but only over relatively long time horizons.

The present study differs from this literature in two important respects. Firstly, we consider simultaneously industry- and country-specific independent variables to explain the observed changes in trade patterns. Secondly, by using a dynamic dependent variable we are able to analyse the importance of both changes and initial levels of the independent variables. In this regard, our approach is closely related to a recent study by Tingvall (2004). Using data for 22 manufacturing industries in 10 European countries, Tingvall analyses the importance of changes and initial levels of industryand country-specific variables to explain changes in an industry-level coefficient of specialization. Tingvall's study convincingly demonstrates the importance of considering both these types of variables for explaining specialization dynamics. Indeed, he finds that scale economies, technology and factor endowments are important drivers of changes in trade patterns. ${ }^{3}$ Unlike his study, however, we consider a dependent variable that indicates whether the trade expansion contributed to reinforce or weaken the countries' previous specialization. In addition, we use a sample that covers a larger set of OECD countries, thereby comprising a more skewed distribution of factor endowments, and comparably large divergence in productivity and market size. We find that industry-specific changes in labour productivity and relative labour costs were important drivers of changes in trade patterns in the OECD. Our results also indicate that trade liberalization contributed to an increase in the previous specialization of larger OECD economies in industries with increasing returns to scale, a finding that is consistent with the new economic geography models. Lastly, we find some evidence that initial endowments of human capital contributed to explain the pattern of trade expansion following trade liberalization. By contrast, we find no

\footnotetext{
3 The importance of considering both industry- and country-specific forces based on the insights of different trade models to explain the dynamics of international specialization is also highlighted by Forslid et al. (2002). Using a large scale CGE-model to analyse the effects of European integration on the location of industrial production, the authors find that the dynamics of specialization that follows gradual reductions in trade costs is determined by comparative advantage (based on differences in endowments and technology across countries) and industrial characteristics such as scale economies and backward and forward linkages.
} 
evidence that changes in factor endowments were significant drivers of the observed dynamics of trade patterns. This may reflect the fact that changes in endowments only become important drivers of specialization dynamics over relatively long time horizons. The remainder of the paper is organized as follows. Section 2 introduces the new dynamic measures for analysing changes in international trade patterns. Section 3 describes the data used. Section 4 presents descriptive evidence on the dynamics of international trade patterns in 20 OECD countries over the 1980-2000 period. Section 5 describes the regression variables and outlines the estimates on the determinants of inter-industry trade dynamics. Section 6 concludes.

\section{Measuring the Dynamics of International Trade Patterns}

In this section, we propose a set of new dynamic measures for investigating the dynamics of international trade patterns. An important attribute of the indexes proposed below is that they capture both the structure and the direction of the trade expansion. More specifically, they allow us to decompose the change in trade into three different components: inter-industry trade changes that contribute to increase a country's previous specialization, marginal intra-industry trade, and inter-industry trade changes that contribute to weaken a country's previous specialization (specialization shifts).

To construct these measures, we start from the marginal intra-industry trade index (MIIT) proposed by Brülhart (1994). This measure consists of a transposition of the Grubel and Lloyd (1975) intra-industry trade index $(G L)$ to a dynamic setting, and is defined as:

$$
\operatorname{MIIT}_{i j t}=1-\operatorname{INTER}_{i j t}=1-\frac{\left|\Delta_{t} X_{i j}-\Delta_{t} M_{i j}\right|}{\left|\Delta_{t} X_{i j}\right|+\left|\Delta_{t} M_{i j}\right|},
$$

where $\Delta_{t} X_{i j}$ and $\Delta_{t} M_{i j}$ represent, respectively, the change in exports and imports in industry $i$ from country $j$ in period $t .{ }^{4}$ The $M I I T_{i j t}$ index gives the proportion of trade change that is matched in each sector. Like the GL index, it can take any value between 0 and 1 . If $M I I T_{i j t}=0$, all marginal trade in industry $i$ from country $j$ is of the inter-industry type. By contrast, when $M I I T_{i j t}=1$ trade expansion is entirely of the intra-industry type.

4 This contribution followed the pioneer work of Hamilton and Kniest (1991), the first study pointing out the importance of using dynamic measures to study the dynamics of intra-industry trade. 
Since its introduction, the MIIT index has been widely used in the literature on trade-induced labour market adjustment. ${ }^{5}$ Despite its dynamic nature, however, the usefulness of this measure for the purposes of this paper is limited. This is because the unmatched component of marginal trade aggregates, and hence does not distinguish between, two opposite changes in the pattern of trade: Inter-industry flows that contribute to an increase in the previous specialization (IPS), and inter-industry movements that contribute to weaken a country's previous specialization, which we name specialization shifts (SS). In order to investigate the dynamics of international trade patterns, we decompose the unmatched (interindustry) marginal trade of industry $i$ from country $j$ into these two different components:

$$
\operatorname{INTER}_{i j t}=\left\{\begin{array}{c}
\operatorname{IPS}_{i j t} \text { if } \operatorname{sign}\left(\Delta_{t} X_{i j}-\Delta_{t} M_{i j}\right)=\operatorname{sign}\left(X_{i j 0}-M_{i j 0}\right) \\
\operatorname{SS}_{i j t} \text { if sign }\left(\Delta_{t} X_{i j}-\Delta_{t} M_{i j}\right) \neq \operatorname{sign}\left(X_{i j 0}-M_{i j 0}\right)
\end{array},\right.
$$

where $X_{i j 0}$ and $M_{i j 0}$ represent, respectively, the exports and imports of industry $i$ from country $j$ at the beginning of period $t$. From (2) it stands clear that, in each period $t$, the unmatched marginal trade in industry $i$ from country $j$ is either $I P S_{i j t}$ or $S S_{i j t}$. Specialization shifts may be caused either by a decrease in net exports in net exporting industries or by a fall in net imports in import competing sectors. Conversely, an increase in the previous specialization may be caused either by a rise in net exports in net export industries or by an increase in net imports in import competing industries.

In Sections 4 and 5, these measures are used, inter alia, to describe the dynamics of trade patterns in 20 OECD countries and as the dependent variable in econometric analysis. In the econometric analysis, we aim to investigate the role of both industry- and country-specific regressors in explaining the observed changes in the pattern of trade. For this purpose, we shall define a dependent variable that captures the change in trade at the level of the industry, for each of the countries studied. In addition, we seek to use a dependent variable that captures the direction of the change in international specialization. For these reasons, it is convenient to define the dependent variable as (IPS - SS $)_{i j t}$. Note that, in a given period $t$, the marginal inter-industry trade in industry $i$ from country $j$ consists of either

5 See, for example, Brülhart et al. (1999), Brülhart (2000), Brülhart and Elliot (2002), Cabral and Silva (2006). 
$I P S_{i j t}$ or $S S_{i j t}$. Therefore, (IPS - SS $)_{i j t}$ captures simultaneously the magnitude and the direction of the change in trade in each industry. A value close to $1(-1)$ indicates that most marginal trade in industry $i$ was unmatched and that the trade expansion contributed to reinforce (weaken) the country's previous inter-industry specialization. A value close to 0 indicates that most trade expansion consisted of matched flows, and hence that inter-industry specialization did not change significantly.

For undertaking descriptive analysis on the dynamics of trade patterns, it is more convenient to report country-level weighted averages of IPS, MIIT and SS. A country-level weighted average of these measures can be obtained by applying the following formulas:

$$
\begin{aligned}
& I P S_{j t}=\sum_{i=1}^{n} k_{i t} I P S_{i j t}, \quad M I I T_{j t}=\sum_{i=1}^{n} k_{i t} M I I T_{i j t} \\
& \text { and } S S_{j t}=\sum_{i=1}^{n} k_{i t} S S_{i j t}
\end{aligned}
$$

where,

$$
k_{i t}=\frac{\left|\Delta_{t} X_{i j}\right|+\left|\Delta_{t} M_{i j}\right|}{\sum_{i=1}^{n}\left(\left|\Delta_{t} X_{i j}\right|+\left|\Delta_{t} M_{i j}\right|\right)} .
$$

Thus, by using (1)-(4) we may compute a set of country-level weighted measures of IPS, MIIT and SS where the weights $\left(k_{i t}\right)$ are simply the shares of the industries in the country's total trade change.

\section{Data}

In the descriptive analysis conducted in Section 4, we make use of data for multilateral exports and imports from manufacturing in 20 OECD countries over the 1980-2000 period. Our trade data come from two sources. The first is the World Bank's Trade and Production Database, covering 28 industries at the 3-digit international standard industrial classification (ISIC), as described in Nicita and Olarreaga (2001). The second is the OECD's International Trade by Commodities Statistics, which comprises more disaggregated data at the 3- and 4-digit levels of standard international trade classification (SITC). Because of missing data for the independent variables, in the econometric analysis we are forced to restrict the sample to $26 \mathrm{manu}-$ facturing industries from 20 OECD countries over the 1980-1990 period 
(divided in two five-year intervals). ${ }^{6}$ Industry-level data for the dependent and independent variables come from the Trade and Production Database. The sources of the country-level data for the explanatory variables are the 5.6 and 6.1 versions of the Penn World Tables and the Barro-Lee Database on educational attainment.

\section{Descriptive Empirics}

Descriptive statistics on $M I I T_{j t}, I P S_{j t}$ and $S S_{j t}$ are presented in Tables 1 and 2. As can be seen, specialization shifts represent a significant part of the trade expansion in most of the countries studied. Indeed, particularly over the periods 1980-1985 and 1995-2000, their relative importance has often revealed to be greater than that of increase in the previous specialization. In addition, it is clear that, as the level of statistical disaggregation increases, the importance of MIIT tends to decrease in favour of IPS and SS.

These results therefore indicate that in many OECD countries increased openness to trade did not induce an increase in the overall degree of international specialization. Indeed, over the periods 1980-1985 and 19952000 , most of the countries studied have experienced a decrease in the degree of international specialization. Although based on different data and methods, these results are consistent with the previous empirical research on specialization dynamics. Amiti (1999) examines the evolution of the Gini coefficient of industrial concentration for a sample of EU countries and industries. She finds evidence of increased specialization in 6 of the 10 countries studied and increased concentration in less than half of the 65 industries analyzed. Proudman and Redding (2000) investigate the evolution of international trade patterns in the G-5 economies over the 1970-1993 period by examining changes in the distribution of a modified version of the Balassa (1965) RCA index across 22 manufacturing industries. They show that trade patterns experienced substantial mobility over time but find no evidence of an increase in the degree of international specialization in 4 of the 5 countries studied. Brasili et al. (2000) extend this analysis by considering two groups of countries, at different stages of economic development. They find that, by comparison with advanced nations, the 'new industrialized countries' included in the sample exhibited a higher degree of

6 The industries ISIC 'Petroleum refineries' and ISIC 354 'Miscellaneous petroleum and cool products' were excluded because of missing data for the regressors. 


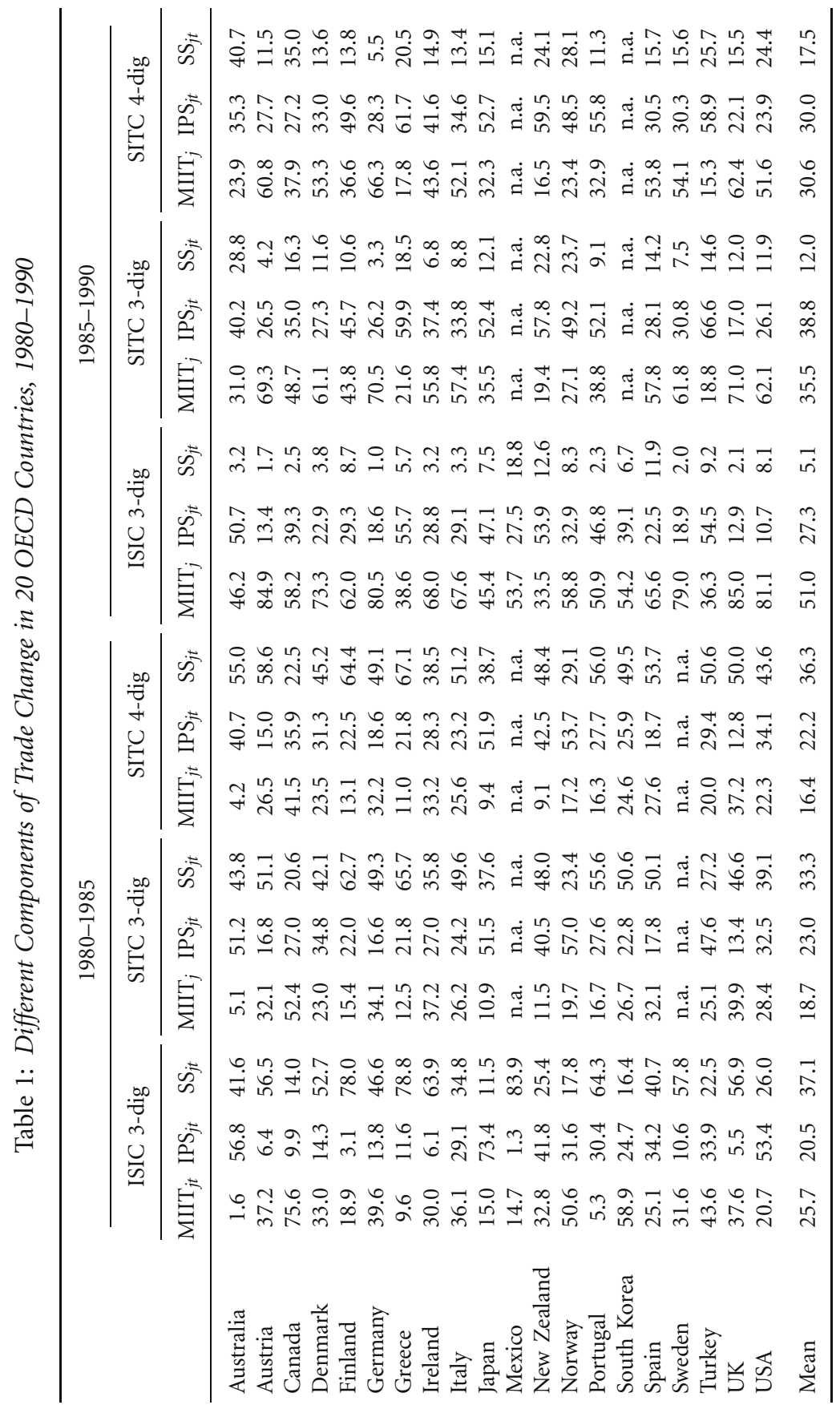




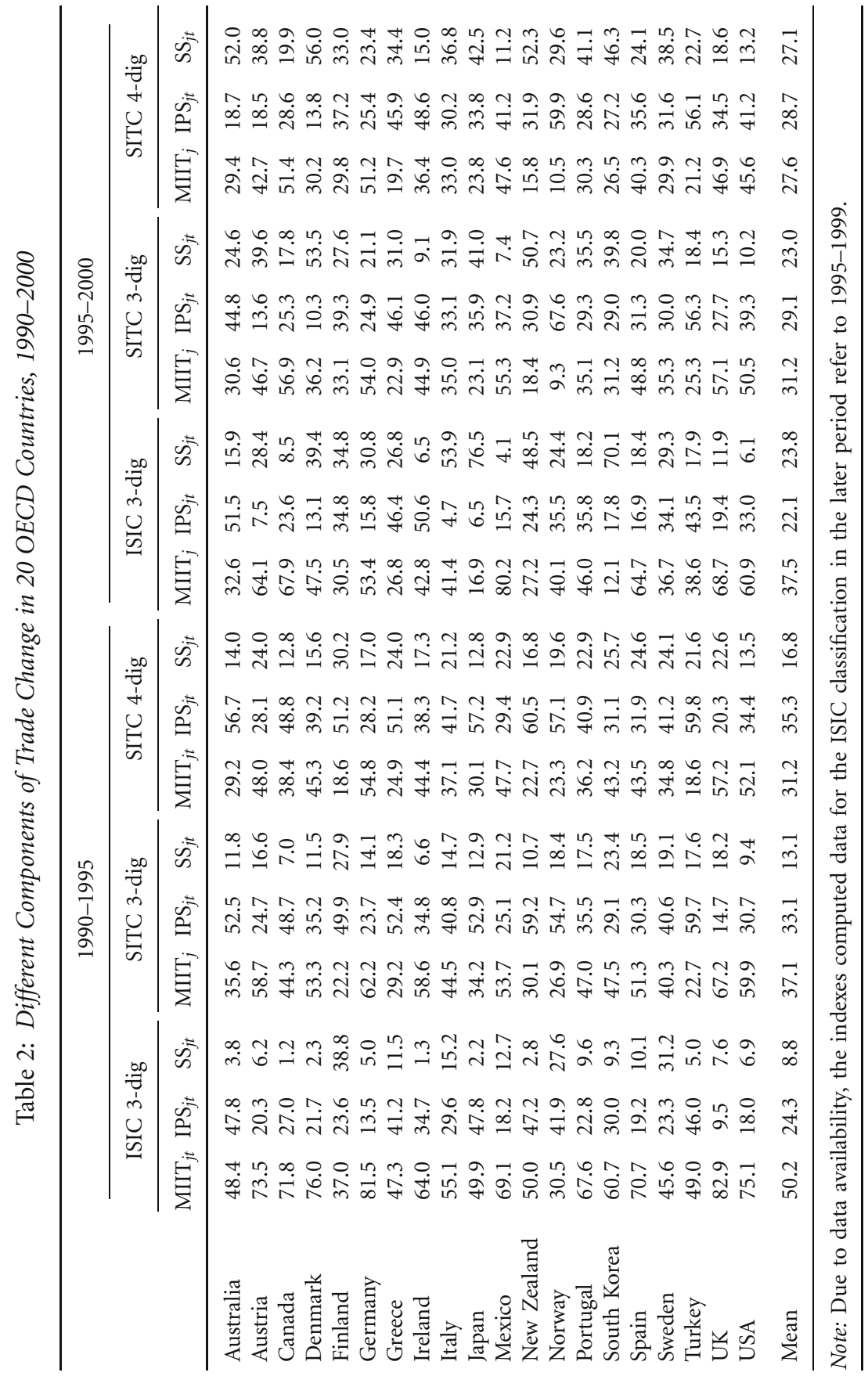


mobility in trade patterns. In addition, they find that none of these groups of countries experienced an increase in the degree of international specialization during 1970-1995. Redding (2002) uses a similar methodology to analyse changes in output shares across 20 industries in 7 OECD countries. Once again, he finds no evidence of an increase in the degree of overall specialization in most of the countries studied.

In line with this evidence, several papers have documented a sharp rise in intra-industry trade in most OECD countries (see, for example, Fontagné et al. 1997). One of the main contributions of the present analysis is to show that, in many of these countries, the observed rise in intraindustry trade did not occur mainly because of matched trade expansion but indeed because of specialization shifts. This is an interesting finding as the existence of specialization shifts cannot be explained in the context of static intra-industry trade models with identical countries (e.g. Krugman 1979; Brander 1981). Furthermore, the dominance of specialization shifts in the trade expansion of several countries indicates that the self-reinforcing mechanisms highlighted by the theoretical models of trade and growth (Krugman 1987; Lucas 1988; Grossman and Helpman 1991; Redding 1999) do not find convincing support in the data. By contrast, it suggests that other forces, such as factor accumulation and international knowledge spillovers, may be more important drivers of the observed changes in the pattern of trade. The present analysis, however, also documents important differences among periods. Indeed, during 1985-1995, the $I P S_{j t}$ component dominated the trade expansion in several OECD countries, indicating that they have experienced an increase in the degree of international specialization in this period.

\section{Explaining the Dynamics of Trade Patterns}

What are the fundamental drivers of the observed changes in the patterns of trade? We investigate this question by considering both industry- and country-specific explanatory variables motivated by the traditional and the new trade theories. Based on the standard Heckscher-Ohlin model, we consider the importance of both changes and initial levels of countries' factor endowments. Motivated by the models of the new economic geography, we analyse the role played by increasing returns to scale, market size and intensity in intermediate goods. In line with the models of trade and growth, we examine the role played by industry-specific changes in 
relative labour productivity and labour costs in explaining the observed changes of trade patterns. The construction of each of these explanatory variables and its expected relationship with the dependent variable is discussed below.

\subsection{Explanatory Variables}

\subsubsection{Trade Liberalization, Industry Factor Intensity, and Country Initial Endowments}

In the context of the Heckscher-Ohlin model, in a world of fixed endowments, trade liberalization is expected to induce an increase in a country's net exports (imports) in the industries that are intensive in a country's abundant (scarce) factor endowments. As shown by Helpman (1981) and Helpman and Krugman (1985), comparative advantage according to the neoclassical trade theory is expected to dominate the trade expansion in the presence of significant differences between countries' relative endowments. By contrast, when countries have similar relative factor supplies, intra-industry trade expansion is expected to dominate. Hence, if industries are sensitive to the neoclassical determinants of international specialization and trading partners differ widely in terms of relative endowments, trade liberalization is expected to induce an inter-industry trade expansion that reinforces the countries' previous specialization.

To investigate this hypothesis, we construct an interaction term that aims to capture all these three elements. Firstly, we shall proxy trade liberalization with the variation in the industry's openness to trade $\left(\Delta_{t} O p e n_{i j}\right){ }^{7}$ Secondly, following Amiti (1999), an industry's sensitiveness to the neoclassical determinants is captured by the deviation of its factor intensity from the country mean

$$
\operatorname{Fact}\left(e_{i j t}\right)=\left|\frac{e_{i j t}}{\bar{e}_{j t}}-1\right|
$$

where $e_{i j t}$ represents industry's $i$ factor intensity and $\bar{e}_{j t}$ the average industry factor intensity in the corresponding country. We consider intensity in physical $\left(e_{i j t}=k_{i j t}\right)$ and human capital $\left(e_{i j t}=h_{i j t}\right)$. Physical capital intensity is measured by the ratio between fixed capital formation and the number

7 Where $\Delta_{t}$ Open $_{i j}=O p e n_{i j F}-O p e n_{i j 0}$, with $O p e n_{i j F}=\left(X_{i j F}+M_{i j F}\right) / Y_{i j F}$ and $O p e n_{i j 0}=$ $\left(X_{i j 0}+M_{i j 0}\right) / Y_{i j 0}$. 
of employees. As in Amiti (1999), we shall proxy intensity in human capital with average wages per employee. Lastly, in order to capture differences in countries' initial endowments, we shall use the variable

$$
\operatorname{Initial}\left(E_{j t}\right)=\left|\frac{E_{j o}}{\bar{E}_{0}}-1\right| \text {, }
$$

where $E_{j 0}$ represents the relative factor endowments of country $j$ at the beginning of period $t$, and $\bar{E}_{0}$ is the average of this variable in all countries $\left(\bar{E}_{0}=\frac{1}{m} \sum E_{j 0}\right)$. We consider two relative factor supplies: Physical capital stock per worker $\left(E_{j t}=K_{j t}\right)$ and human capital stock per worker $\left(E_{j t}=H_{j t}\right)$. Our data on physical capital per worker come from the Penn World Tables. Human capital per worker is measured by the proportion of the population over 25 years with at least some higher education. Data for this variable come from the Barro-Lee data set. For the reasons outlined above, the effect of increased industry openness on the degree of international specialization is expected to be jointly influenced by the industry's sensitivity to neoclassical determinants, and the country's relative position in terms of initial endowments. In other words, the impact of increased openness on the dependent variable is expected to depend positively upon the level of the interaction term Fact $\left(e_{i j t}\right) \times \operatorname{Initial}\left(E_{j t}\right)$. Hence, we expect a positive relationship between the three-way interaction term $\left.\Delta_{t} \operatorname{Open}_{j t} \times \operatorname{Fact}_{(i j t}\right) \times \operatorname{Initial}\left(E_{j t}\right)$ and the dependent variable. ${ }^{8}$

\subsubsection{Industry Factor Intensity and Changes in Country Factor Endowments}

In the context of the Heckscher-Ohlin model, changes in relative factor endowments can contribute either to reinforce or to attenuate countries' previous international specialization, depending upon whether they lead to a process of divergence or convergence of relative factor supplies among trade partners. In order to investigate the effect of changes in relative endowments on inter-industry trade dynamics, we consider the interaction term $\operatorname{Fact}\left(e_{i j t}\right) \times \operatorname{Diverg}\left(E_{j t}\right)$. As defined in (5), the variable Fact $\left(e_{i j t}\right)$ aims to capture the industry's sensitivity to the Heckscher-Ohlin determinants.

${ }^{8}$ Note that this hypothesis is made under the assumption that relative factor supplies are fixed. For this reason, when these variables are included in regression analysis we control for its change during period $t$. 
$\operatorname{Diverg}\left(E_{j t}\right)$, in turn, is intended capture the effect of changes in endowments. This variable is defined as

$$
\operatorname{Diverg}\left(E_{j t}\right)=\left\{\begin{array}{c}
\left|\frac{E_{j F}}{\overline{E_{F}}}-1\right|-\left|\frac{E_{j 0}}{\overline{E_{0}}}-1\right| \\
\text { if } \operatorname{sign}\left(\frac{E_{j F}}{\overline{E_{F}}}-1\right)=\operatorname{sign}\left(\frac{E_{0}}{\overline{E_{0}}}-1\right) \\
-\left|\frac{E_{j F}}{\overline{E_{F}}}-1\right|-\left|\frac{E_{j 0}}{\overline{E_{0}}}-1\right| \\
\text { if } \operatorname{sign}\left(\frac{E_{j F}}{\overline{E_{F}}}-1\right) \neq \operatorname{sign}\left(\frac{E_{0}}{\overline{E_{0}}}-1\right)
\end{array},\right.
$$

where $\left(E_{j F}\right)$ represents the relative factor endowments of country $j$ at the end of period $t$, and $\bar{E}_{F}$ is the average of this variable in all countries $\left(\bar{E}_{F}=\frac{1}{m} \sum E_{j F}\right)$. A positive sign for this variable indicates that the relative factor supplies of country $j$ diverged from the OECD mean during period $t$. Conversely, a negative sign indicates a change in the opposite direction that may (or not) lead to a reversion of the country's initial relative position. Therefore, we expect a positive relationship between the interaction term $\left.\operatorname{Fact}_{i j t}\right) \times \operatorname{Diverg}\left(E_{j t}\right)$ and the dependent variable.

\subsubsection{Trade Liberalization, Increasing Returns to Scale, Market Size and Intensity in Intermediate Goods}

In a nutshell, the models of the new economic geography suggest that a fall in trade costs may contribute to the agglomeration of industries with increasing returns to scale in larger economies (Krugman and Venables 1990) and to an increase in the degree of geographical concentration of industries linked by the use of intermediate goods (Krugman and Venables 1995; Venables 1996). These models also predict, however, that agglomeration may be reversed once trade costs fall below a critical level. Therefore, under this framework, the direction of inter-industry trade dynamics depends upon whether a reduction in trade costs induces agglomeration or dispersion of manufacturing activities across countries. While agglomeration would contribute to an increase in the previous specialization, dispersion would explain specialization shifts. In order to investigate these effects, we consider two interaction terms. Firstly, the interaction between the change in industry i's trade openness, the degree of scale economies and the market size of the corresponding country $\left(\Delta_{t} \mathrm{Open}_{j t} \times\right.$ Scale $_{i j t} \times$ MSize $\left._{j t}\right)$. Following Kim (1995) and Amiti (1999), the degree of scale economies in industry $i$ from 
country $j$ is measured by the average firm size

$$
\text { Scale }_{i j t}=\left(\frac{L}{\text { Firms }}\right)_{i j t},
$$

where $L_{i j t}$ is the number of employees in the industry and Firms number of firms. Market size is measured by the country's initial GDP. If trade expansion induces an increase in the previous specialization of large economies in scale intensive industries we would expect the sign of the coefficient associated with this interaction terms to be positive. Secondly, we shall consider the interaction between $\Delta_{t}$ Open $_{j t}$ and a variable that measures each industry's intensity in intermediate goods Interm $_{i j t}$. As in Amiti (1999), intensity in intermediate goods is measured by:

$$
\text { Interm }_{i j t}=\left(\frac{Y-V A}{Y}\right)_{i j t},
$$

where $Y_{i j t}$ and $V A_{i j t}$, are, respectively, the mean of production and value added of industry $i$ from country $j$ over period $t .{ }^{9}$ If an increase in openness induces an increase (decrease) in the degree of geographic concentration of industries with high use of intermediate goods, we would expect a positive (negative) sign for the coefficient associated with $\Delta_{t}$ Open $_{j t} \times$ Interm $_{i j t}$.

\subsubsection{Changes in Relative Labour Productivity and Wages}

Dynamic models of trade and growth examine the impact of changes in labour productivity on the evolution of international specialization. One strand of this theoretical literature (Krugman 1987; Lucas 1988; Redding 1999) argues that sector-specific learning by doing (national in scope) produces self-reinforcing mechanisms that contribute to increase countries' initial comparative advantage. This is because sector-specific learning by doing leads to an increase in labour productivity in the industries in which countries were already relatively more productive (and hence specialized). Other models, however, suggest that international knowledge spillovers and technology transfer may induce a rise in labour productivity in the industries in which countries were previously relatively less efficient. In such

9 In contrast with Amiti (1999), in the present study the variables Scale $e_{i j t}$ and Intermijt are computed with country-specific data for each industry. We use the average of the individual terms that compose these variables over the corresponding five-year period. 
a case, changes in labour productivity would contribute to weaken (or even reverse) the previous patterns of international specialization.

Therefore, depending on its direction, industry-specific changes in labour productivity may explain either $I P S_{i j t}$ or $S S_{i j t}$. In order to capture the influence of these mechanisms in explaining the dynamics of international trade patterns, we construct an indicator of comparative advantage based on the relationship between relative labour productivity and relative labour costs in industry $i$ from country $j$ :

$$
P_{i j t}=\frac{(V A / L)_{i j t}}{\overline{(V A / L)}_{i t}}-\frac{(W / L)_{i j t}}{\overline{(W / L)_{i t}}},
$$

where $(V A / L)_{i j t}$ and $(W / L)_{i j}$ are, respectively, labour productivity and wages in industry $i$ from country $j$, while $(\overline{V A / L})_{i j}$ and $(\overline{W / L})_{i j}$ represent, respectively, the average of labour productivity and wages in industry $i$ in the 20 OECD countries included in the sample. To analyse the effect of changes in this indicator on inter-industry trade dynamics, we construct the following variable:

$$
\operatorname{Diverg}\left(P_{i j t}\right)=\left\{\begin{array}{ll}
\left|P_{i j F}\right|-\left|P_{i j 0}\right| & \text { if } \quad \operatorname{sign}\left(P_{i j F}\right)=\operatorname{sign}\left(P_{i j 0}\right) \\
-\left|P_{i j F}\right|-\left|P_{i j 0}\right| & \text { if } \quad \operatorname{sign}\left(P_{i j F}\right) \neq \operatorname{sign}\left(P_{i j 0}\right)
\end{array} .\right.
$$

A positive sign for this variable indicates a change in the indicator of comparative advantage that tends to reinforce the initial relative position of country $j$ in industry $i$. Conversely, a negative sign indicates a change that contributes to weaken (or even reverse) the country's previous specialization in that industry. Hence, we expect a positive relationship between this variable and the dependent variable.

\subsection{Econometric Model and Results}

To investigate the dynamics of trade patterns in the OECD, we use the panel structure of the data in the following general equation:

$$
(I P S-S S)_{i j t}=f\left(C_{j t}, I_{i j t}, \delta_{j}, v_{i}, \tau_{t}, \varepsilon_{i j t}\right),
$$

where $i \in\{1, \ldots, 26\}$ denotes industries, $j \in\{1, \ldots, 20\}$ countries, and $t=\{1,2\}$ periods. $C_{j t}$ is a vector of country-specific observable characteristics and $I_{i j t}$ is a vector of industry-specific observable attributes, as defined 
in the previous sub-section. $\delta_{j}$ is an unobservable country-specific effect, $\tau_{t}$ is an unobservable industry-specific effect, and $\tau_{t}$ is an unobservable period-specific effect. $\varepsilon_{i j t}$ is an error term.

Table 3: Descriptive Statistics: Regression Data

\begin{tabular}{|c|c|c|}
\hline Variable & Mean & Std. Dev. \\
\hline$(I P S-S S)_{i j t}$ & 0.066 & 0.663 \\
\hline$(1 / 2) \times\left(1+(I P S-S S)_{i j t}\right)$ & 0.533 & 0.330 \\
\hline Initial $(K)_{j t}$ & 0.358 & 0.243 \\
\hline $\operatorname{Diverg}(K)_{j t}$ & -0.006 & 0.060 \\
\hline Initial $(H)_{j t}$ & 0.547 & 0.438 \\
\hline Diverg $(H)_{j t}$ & -0.043 & 0.106 \\
\hline$M$ Mize $_{j t}$ & 529.946 & 943.800 \\
\hline$\Delta O p e n_{i j t}$ & 0.099 & 0.616 \\
\hline Fact $\left(k_{i j t}\right)$ & 0.555 & 0.785 \\
\hline Fact $\left(h_{i j t}\right)$ & 0.171 & 0.130 \\
\hline Scale $_{i j t}$ & 0.058 & 0.126 \\
\hline Interm $_{i j t}$ & 0.581 & 0.115 \\
\hline $\operatorname{Diverg}\left(P_{i j t}\right)$ & 0.011 & 0.171 \\
\hline Observations & \multicolumn{2}{|c|}{1,040} \\
\hline
\end{tabular}

Note: The variables Scale $e_{i j t}$ and MSize $_{j t}$ have been divided, respectively, by $10^{3}$ and $10^{6}$.

Descriptive statistics on the regression variables are reported in Table 3. A potential problem of performing regression analysis with $(I P S-S S)_{i j t}$ as the dependent variable is that it is bounded by construction in the interval $[-1,1]$. Under these circumstances, the OLS estimator may lead to predictions of the dependent variable outside the extreme points. Furthermore, when there are many observations lying at the boundaries of the interval (or near them), linear regression is likely to produce biased estimates due to its inability to deal with the inherent nonlinearities around those regions. We shall address this problem by employing the quasi-likelihood method of estimation for bounded dependent variables proposed in Papke and Wooldridge (1996). This methodology integrates the Generalized Linear Model (GLM) from the statistical literature (McCullagh and Nelder 1989) and the quasi-likelihood method from the econometric literature (Gourieroux et al. 1984). ${ }^{10}$ In line with Moulton $(1986,1990)$, adjustment is made

10 For a recent application of this methodology in a trade context see, for example, Kneller and Pisu (2004). This method is only applicable when the dependent variable is 
for within correlation between error arising from country-level variables being combined with data on individual industries. ${ }^{11}$

We start by estimating the basic model, including only independent variables based on the $\mathrm{H}-\mathrm{O}$ theory. The model is then augmented to examine the role played by variables based on the new economic geography and the trade and growth literature. For each set of explanatory variables, we report the estimated results with and without the inclusion of industry- and country-dummies. As discussed above, to investigate some of the hypotheses formulated in the previous sub-section we are interested in the coefficients associated with two- and three-way interaction terms. This is because the effect of one explanatory variable on the dependent variable depends in part on the level of a second explanatory variable (in the case of a two-way interaction term) or upon the level of two other explanatory variables (in the case of a three-way interaction term). To capture the unique effect of a higherorder interaction term, we shall include simultaneously in the regressions all lower-order interaction terms and the corresponding individual variables (see Aiken and West 1991). For the sake of brevity, only the coefficients and the marginal effects of the interaction terms of interest are reported. The main regression results are shown in Table 4 . We then check the sensitivity of the estimates to different specifications by including the regressors based on different theoretical frameworks separately. Table 5 presents the corresponding results. As can be seen, the results are robust to different specifications. Therefore, our main findings are summarized in Table 4.

The econometric results give some support to the hypothesis that initial levels of human capital are an important determinant of the observed dynamics of trade patterns. The coefficient associated with the interaction term $\Delta_{t}$ Open $_{j t} \times$ Fact $\left(h_{i j t}\right) \times \operatorname{Initial}\left(H_{j t}\right)$ presents, as expected, a positive sign and is statistically significant at the 10 per cent level in all specifications.

The finding that initial factor endowments are an important factor driving changes in trade patterns is consistent with the results of Tingvall (2004) and Forslid et al. (2002). Using a sample for 22 industries in $10 \mathrm{EU}$ countries, Tingvall finds that initial endowments of physical capital are a significant determinant of changes in the European industrial structure. Forslid et al. (2002) use a large scale CGE model to analyse the effects of European inte-

bounded in $[0,1]$. For this reason we transform the dependent variable in order to lie in this interval by applying the formula $(1 / 2)\left[1+(I P S-S S)_{i j t}\right]$.

11 In all regressions, the standard errors are clustered by country and period using the option "cluster" in Stata. 
Bastos/Cabral: The Dynamics of International Trade Patterns

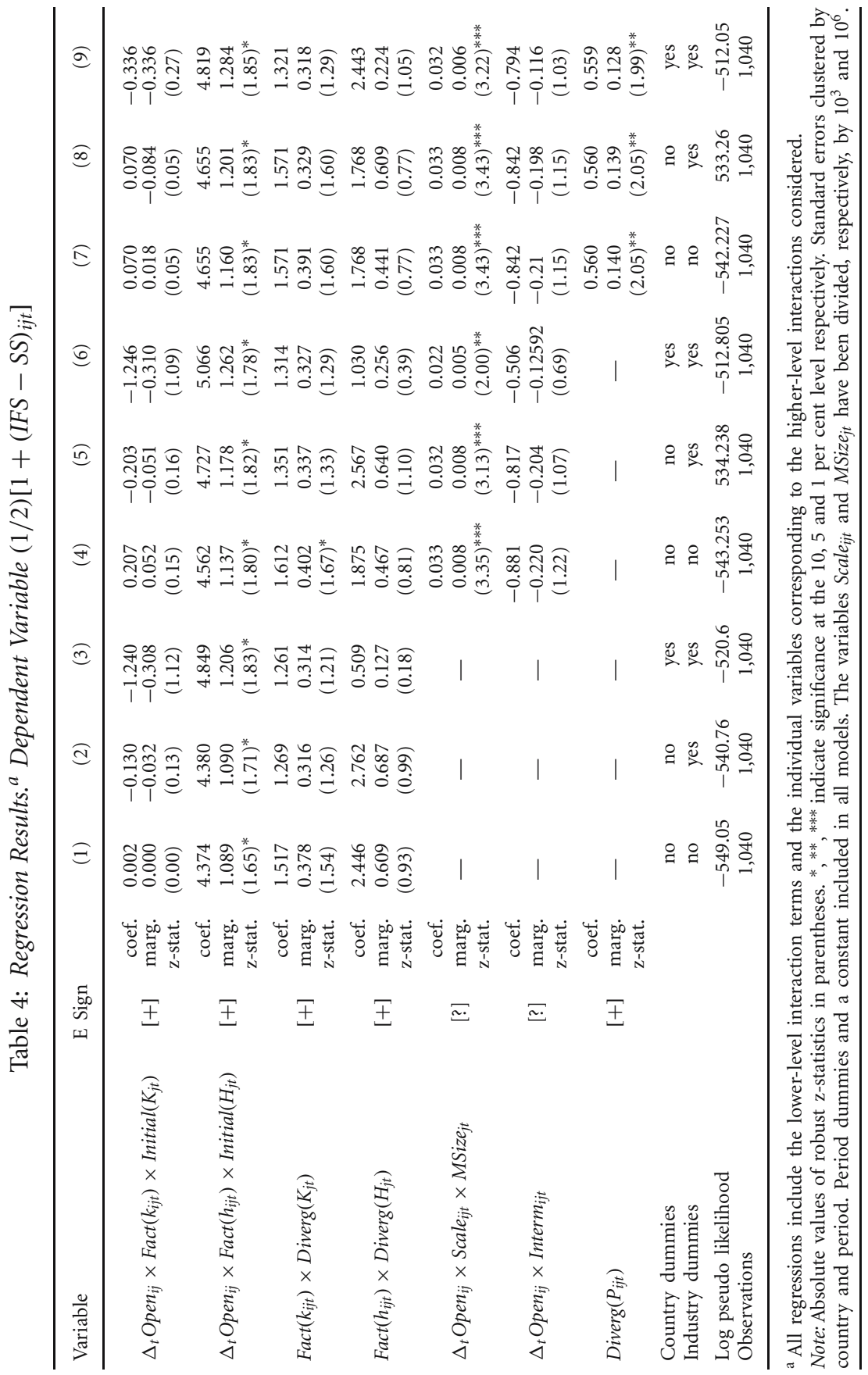


Review of World Economics 2007, Vol. 143 (3)

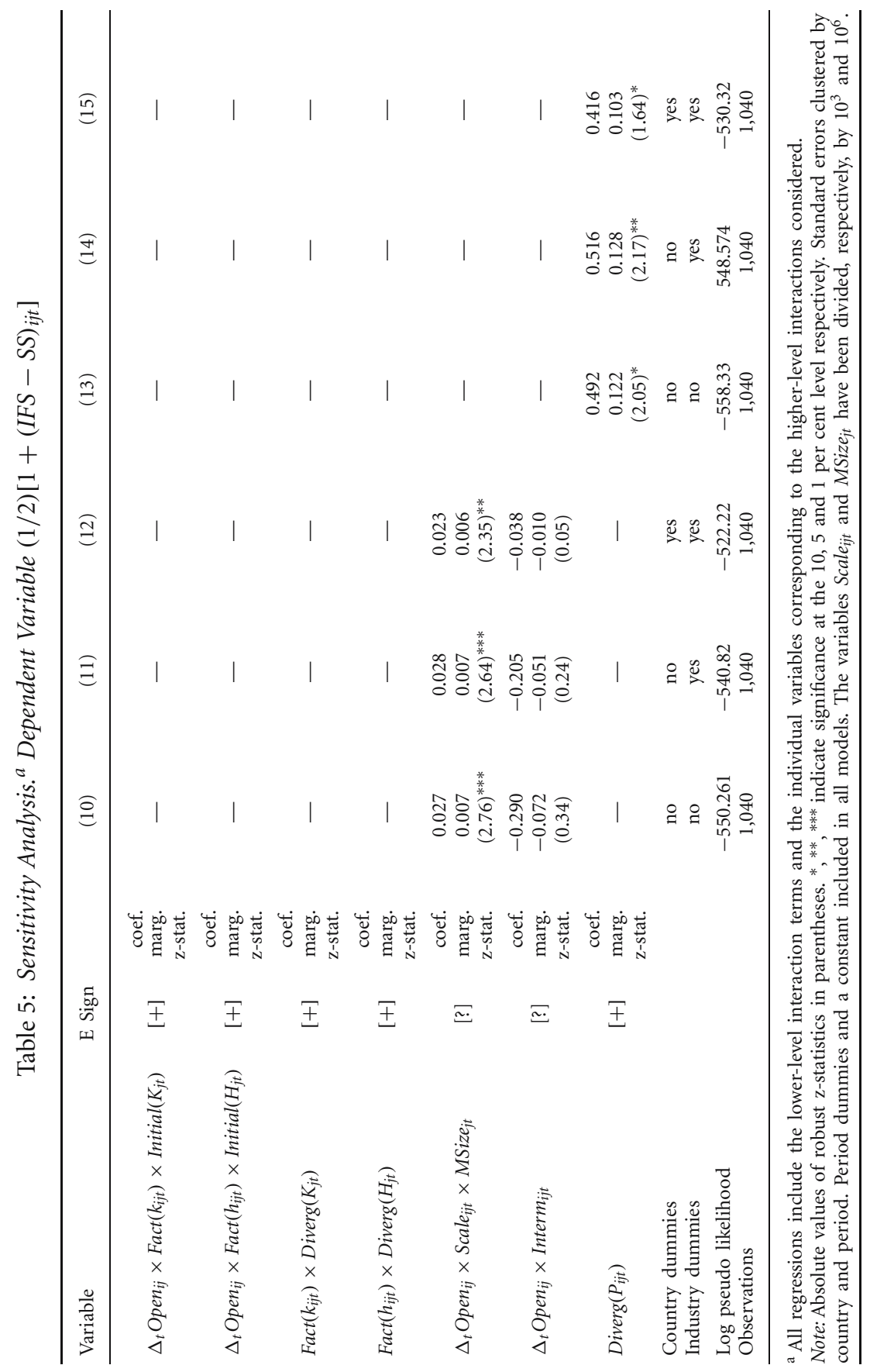


gration on industrial location and find that industries relatively more sensitive to comparative advantage become monotonously more concentrated as trade costs fall. This evidence does not stand, however, for initial levels of physical-capital per worker. As can be seen in Table 4, the coefficient associated with $\Delta_{t} \operatorname{Open}_{j t} \times \operatorname{Fact}\left(k_{i j t}\right) \times \operatorname{Initial}\left(K_{j t}\right)$ is always insignificant. The result that human capital endowments are more important than supplies of physical capital for explaining international specialization in developed countries is consistent with the findings of Harrigan (1997). Using a sample of ten OECD countries for 1970-1990, Harrigan finds robust evidence that human capital endowments (but not physical capital) are significantly associated with countries' production structure in manufacturing.

As can be seen in Table 4, the econometric results do not provide support to the hypothesis that the observed changes in trade patterns were driven by changes in relative factor endowments. The coefficients of the interaction terms Fact $\left(k_{i j t}\right) \times \operatorname{Diverg}\left(K_{j t}\right)$ and $\operatorname{Fact}\left(h_{i j t}\right) \times \operatorname{Diverg}\left(H_{j t}\right)$ present the expected sign but are statistically insignificant in all regressions. In this regard, our results contrast with those of Tingvall (2004), who finds significant effects of changes in human and physical capital endowments on changes in trade patterns of $10 \mathrm{EU}$ countries. A possible justification for the insignificant coefficients is that five-year intervals may not be sufficiently long to capture the effect of changes in endowments on trade patterns. Consistent with this explanation, Redding's (2002) study of 7 OECD economies finds that changes in endowments only become relatively important drivers of specialization dynamics over longer time horizons.

Turning to the variables based on the new economic geography, our results indicate that trade liberalization contributed to reinforce the previous specialization of countries with larger markets in industries with increasing returns to scale. The coefficient of the interaction term $\Delta_{t}$ Open $_{j t} \times S c a l e_{i j t} \times$ MSize $_{j t}$ is positive and strongly significant in all specifications. These results are therefore consistent with Davis and Weinstein $(1999,2003)$, who find evidence in support of economic geography effects using data, inter alia, for Japanese regions and OECD countries. Our results are also consistent with those of Kim (1995) and Amiti (1999) who report that industries with increasing returns to scale exhibited a tendency for increased concentration within the US and the EU. By contrast, Tingvall (2004) finds no evidence of increasing concentration of scale intensive industries on large markets, using the industry's value added as proxy for market size. Therefore, when taken together, this evidence seems to suggest that the country, rather than the industry, is the relevant measure of market size when searching for 
economic geography effects. Also in the context of the economic geography literature, we find no evidence that trade liberalization induced increased specialization in sectors with high intermediate goods usage. The coefficient associated with the interaction term $\Delta_{t} \mathrm{Open}_{j t} \times$ Interm $_{i j t}$ is insignificant in all specifications.

Lastly, we analyse the effects of changes in labour productivity and labour costs at the level of the industry. Our results give strong support to the argument that industry-specific changes in labour productivity and labour costs are an important determinant of inter-industry trade dynamics. As expected, the sign of the coefficient associated with the variable $\operatorname{Diverg}\left(P_{i j t}\right)$ is positive and statistically significant in all specifications. ${ }^{12}$ This result is in accordance with Harrigan (1997), who shows that Ricardian effects are an important determinant of international specialization in the OECD.

\section{Summary and Conclusions}

In this paper, we investigate the dynamics of international trade patterns in 20 OECD countries. Using new dynamic measures, we are able to distinguish between three types of trade change: inter-industry flows that contribute to reinforce a country's previous specialization, marginal intra-industry trade, and inter-industry flows that contribute to a decrease in a country's previous specialization (that we name specialization shifts). Descriptive evidence for 20 OECD countries over the 1980-2000 period indicates that specialization shifts represented a significant part of the observed trade expansion, being often the dominant form of inter-industry trade change. Indeed, we find that in many of the countries studied, the widely documented rise in intraindustry trade did not occur mainly because of matched trade expansion but as a result of specialization shifts. This is an important finding as the existence of specialization shifts cannot be explained in the context of static intra-industry trade models with identical countries. Our results also indicate that trade liberalization did not induce a generalized increase in the degree of international specialization in the OECD. On the contrary, our results suggest that during the periods 1980-1985 and 1995-2000 most of the

12 As pointed out by a referee, changes in labour productivity and labour costs at the level of the industry may also reflect changes in the human capital composition of the workforce. Unfortunately, because of data unavailability, we are not able to account for these changes in the present analysis. This issue deserves to be explored in future research. 
countries studied have experienced a decrease in the degree of international specialization.

The new measures of inter-industry trade dynamics are then used as the dependent variable in regression analysis. Our main findings are as follows. Firstly, in accordance with the predictions of the new economic geography models, our results indicate that trade liberalization contributed to an increase in the previous specialization of larger economies in industries with increasing returns to scale. Secondly, we find support to the hypothesis that Ricardian effects are an important driver of changes in trade patterns in the OECD. Finally, we find some support to the hypothesis that initial endowments of human capital are an important driver of trade expansion following trade liberalization, but no evidence that changes trade patterns were explained by changes in factor endowments. Although this may indicate that factor accumulation is not a strong force driving changes in trade patterns in the OECD, it may also simply reflect the fact that changes in endowments only become an important driver of specialization dynamics over relatively long time horizons.

\section{References}

Aiken, L., and S. West (1991). Multiple Regression: Testing and Interpreting Interactions. Thousand Oaks: Sage.

Amiti, M. (1999). Specialization Patterns in Europe. Weltwirtschaftliches Archiv/ Review of World Economics 135 (4): 573-593.

Balassa, B. (1965). Trade Liberalisation and Revealed Comparative Advantage. Manchester School of Economic and Social Studies 33: 99-123.

Baldwin, R., J. Francois, and R. Portes (1997). The Costs and Benefits of Eastern Enlargement: The Impact on the EU and Central Europe. Economic Policy 12 (24): 125-176.

Brander, J. (1981). Intraindustry Trade in Identical Commodities. Journal of International Economics 11 (1): 1-14.

Brasili, A., P. Epifani, and R. Helg (2000). On the Dynamics of Trade Patterns. De Economist 148 (2): 233-259.

Brülhart, M. (1994). Marginal Intra-Industry Trade: Measurement and Relevance of the Pattern of Industrial Adjustment. Weltwirtschaftliches Archiv/Review of World Economics 130 (3): 600-613.

Brülhart, M. (2000). Dynamics of Intra-Industry Trade and Labour Market Adjustment. Review of International Economics 8 (3): 420-435. 
Brülhart, M., and R. Elliot (2002). Labour Market Effects of Intra-Industry Trade: Evidence for the United Kingdom. Weltwirtschaftliches Archiv/Review of World Economics 138 (2): 207-228.

Brülhart, M., D. McAleese, and M. O’Donnell (1999). Ireland. In M. Brülhart and R. Hine (eds.), Intra-Industry Trade and Adjustment: The European Experience. London: Macmillan.

Cabral, M., and J. Silva (2006). Intra-Industry Trade Expansion and Reallocation between Sectors and Occupations. Review of World Economics/Weltwirtschaftliches Archiv 142 (3): 496-520.

Davis, D., and D. Weinstein (1999). Economic Geography and Regional Production Structure: An Empirical Investigation. European Economic Review 43 (2): 379-407.

Davis, D., and D. Weinstein (2003). Market Access, Economic Geography and Comparative Advantage: An Empirical Test. Journal of International Economics 59 (1): 1-23.

Fontagné, L., M. Frendenberg, M., and N. Péridy (1997). Trade Volumes Inside the Single-Market. CEPII Working Paper 97-07. Centre d'Etudes Prospectives et d'Informations Internationales, Paris.

Forslid, R., J. Haaland, and K. Knarvik (2002). A U-Shaped Europe? A Simulation Study of Industrial Location. Journal of International Economics 57 (2): 273297.

Freeman, R. (2005). Does Globalization of the Scientific/Engineering Workforce Threaten U.S. Economic Leadership? NBER Working Paper 11457. National Bureau of Economic Research, Cambridge, Mass.

Fujita, M., P. Krugman, and A. J. Venables (1999). The Spacial Economy. Cambridge: MIT Press.

Gourieroux, C., A. Monfort, and A. Trognon (1984). Pseudo-Maximum Likelihood Methods. Econometrica 52 (3): 681-700.

Grossman, G., and E. Helpman (1991). Innovation and Growth in the Global Economy. Cambridge: MIT Press.

Grubel, H., and P. Lloyd (1975). Intra-Industry-Trade: The Theory and Measurement of International Trade in Differentiated Products. London: Macmillan.

Hamilton, C., and P. Kniest (1991). Trade Liberalization, Structural Adjustment and Intra-Industry Trade: A Note. Weltwirtschaftliches Archiv/Review of World Economics 127 (2): 356-367.

Harrigan, J. (1997). Technology, Factor Supplies and International Specialization: Estimating the Neoclassical Model. American Economic Review 87 (4): 475-495.

Helpman, E. (1981). International Trade in the Presence of Product Differentiation, Economies of Scale and Monopolistic Competition-A ChamberlinHeckscher-Ohlin Approach. Journal of International Economics 11 (3): 305340.

Helpman, E., and P. Krugman (1985). Market Structure and Foreign Trade. Cambridge, Mass.: MIT Press. 
Kim, S. (1995). Expansion of Markets and the Geographic Distribution of Economic Activities: The Trends in US Regional Manufacturing Structure, 18601987. Quarterly Journal of Economics 111 (4): 881-908.

Kneller, R., and M. Pisu (2004). Export Oriented FDI in the UK. Oxford Review of Economic Policy 20 (3): 424-439.

Krugman, P. (1979). Increasing Returns, Monopolistic Competition, and International Trade. Journal of International Economics 9 (4): 469-479.

Krugman, P. (1987). The Narrow Moving Band, the Dutch Disease and the Competitive Consequences of Mrs Thatcher: Notes on Trade in the Presence of Scale Economies. Journal of Development Economics 27 (1): 41-55.

Krugman, P., and A. Venables (1990). Integration and the Competitiveness of Pheripheral Industry. In C. Bliss and J. Braga de Macedo (eds.). Unit with Diversity in the European Community. Cambridge: Cambridge University Press.

Krugman, P., and A. Venables (1995). Globalization and the Inequality of Nations. Quarterly Journal of Economics 110 (4): 857-880.

Lucas, R. (1988). On the Mechanisms of Economic Development. Journal of Monetary Economics 22 (1): 3-22.

McCullagh, P., and J. Nelder (1989). Generalised Linear Models. New York: Chapman and Hall.

Moulton, B. (1986). Random Group Effects and the Precision of Regression Estimates. Journal of Econometrics 32 (August): 385-397.

Moulton, B. (1990). An Illustration of a Pitfall in Estimating the Effects of Aggregate Variables on Micro Units. Review of Economics and Statistics 72 (2): 334338.

Nicita, A., and M. Olarreaga (2001). Trade and Production, 1976-1999. Policy Research Working Papers 2701. World Bank, Washington, D.C.

OECD (Organisation for Economic Cooperation and Development) (2005). Employment Outlook. Paris: OECD.

Papke, L., and J. Wooldridge (1996). Econometric Methods for Fractional Response Variables with an Application to 401(k) Plan Participation Rates. Journal of Applied Econometrics 11 (6): 619-632.

Proudman, J., and S. Redding (2000). Evolving Patterns of International Trade. Review of International Economics 8 (3): 373-396.

Redding, S. (1999). Dynamic Comparative Advantage and the Welfare Effects of Trade. Oxford Economic Papers 51 (1): 15-39.

Redding, S. (2002). Specialization Dynamics. Journal of International Economics 58 (1): 299-334.

Tingvall, P. (2004). The Dynamics of European Industrial Structure. Review of World Economics/Weltwirtschaftliches Archiv 140 (4): 665-687.

Venables, A. (1996). Equilibrium Locations of Vertically Linked Industries. International Economic Review 37 (2): 341-359. 